\title{
Growth and Neurodevelopment of HIV-Exposed Uninfected Children: a Conceptual Framework
}

\author{
Catherine J. Wedderburn ${ }^{1,2} \cdot$ Ceri Evans ${ }^{3,4}$. Shunmay Yeung ${ }^{1}$ - Diana M. Gibb ${ }^{5} \cdot$ Kirsten A. Donald $^{2}$. \\ Andrew J. Prendergast ${ }^{3,4}$
}

Published online: 15 November 2019

(C) The Author(s) 2019

\begin{abstract}
Purpose of Review The population of HIV-exposed uninfected (HEU) children is expanding rapidly, and over one million HEU infants are born each year globally. Several recent studies have reported that HEU children, particularly in low- and middleincome countries, are at risk of poor outcomes, including impaired growth and neurodevelopment. However, the reasons for poor clinical outcomes amongst HEU children remain unclear.

Recent Findings We summarise the findings from recent large studies that have characterised growth and neurodevelopment in HEU children, identified risk factors and explored underlying mechanistic pathways. We propose a conceptual framework to explain how exposure to HIV and antiretroviral therapy (ART) may lead to adverse growth and neurodevelopment in uninfected children, and review the available evidence and research gaps.

Summary We propose that HEU children are affected both indirectly, through the augmentation of universal risk factors underlying poor growth and neurodevelopment, and directly through HIV/ART-specific pathways, which ultimately may converge through a series of common pathogenic mechanisms. In the era of universal ART, a better understanding of these pathways is crucial to inform future prevention and intervention strategies.
\end{abstract}

Keywords HIV-exposed uninfected $\cdot$ Child $\cdot$ Growth $\cdot$ Stunting $\cdot$ Early child development

\section{Introduction}

Globally, approximately 1.4 million HIV-infected pregnant women give birth each year [1,2]. The increased coverage

Catherine J. Wedderburn and Ceri Evans contributed equally to this work.

This article is part of the Topical Collection on HIV Pathogenesis and Treatment

Ceri Evans

ceri.evans@qmul.ac.uk

1 Department of Clinical Research, London School of Hygiene \& Tropical Medicine, London, UK

2 Department of Paediatrics and Child Health, Red Cross War Memorial Children's Hospital and Neuroscience Institute, University of Cape Town, Cape Town, South Africa

3 Blizard Institute, Queen Mary University of London, London, UK

4 Zvitambo Institute for Maternal and Child Health Research, Harare, Zimbabwe

5 MRC Clinical Trials Unit, University College London, London, UK of antiretroviral therapy (ART) for pregnant and breastfeeding women through prevention of mother-to-child transmission (PMTCT) programs has dramatically reduced perinatal and postnatal HIV transmission. Correspondingly, the global population of HIV-exposed uninfected (HEU) children is increasing and, in 2017, was estimated to have reached 14.8 million [3]. This number will continue to increase with improved PMTCT coverage as over one million HEU children are born every year, the majority of whom are now also exposed to ART [3-5]. Emerging data showing poorer health outcomes of HEU compared to HIV-unexposed children [6] means there is a pressing need to understand and address the mechanisms underlying compromised outcomes.

The Sustainable Development Goals have focused attention on the importance of healthy growth and development, so that children can thrive as well as survive. The in utero period and first 2 years after birth (the first 1000 days) represent a highly sensitive period of development, during which substantial physical growth, including brain maturation, occurs [7]. Early fetal exposures are recognised to have long-term consequences for the child 
and future adult. Given the number of children exposed to HIV and ART in utero, it is important to understand the effects of these exposures. This review will first explore growth and development in HEU children; second, outline a conceptual framework to highlight the pathways through which HIV exposure may impact growth and development; and third, examine how this may help to inform prevention and intervention strategies.

\section{Studies of HIV-Exposed Uninfected Children}

Over recent decades, there has been a growing number of studies evaluating the outcomes of HEU children. However, interpretation of studies can be challenging for several reasons. First, the effects of HIV exposure may differ between high-income and low-income settings. The epidemiology of HIV infection in high-income settings, where adult infections are often found in populations with more substance use and mental health disorders, differs from the more generalised epidemic in subSaharan Africa. In addition, HEU children vary in terms of duration of exposure to both HIV (prenatal/postnatal) and ART and are exposed to different antiretroviral drug classes and combinations. This may mean mechanisms differ across countries. Second, studies are often limited by a lack of comparable HIV-unexposed control groups, particularly due to differences in breastfeeding and socioeconomic status. Third, studies have often been small in size without adequate HIV testing of included children to rule out HIV infection. Fourth, there has been a lack of standardised definitions of outcomes. Despite these limitations, it is possible to draw conclusions on health outcomes from large, well-conducted studies, many of which have clearly demonstrated that HEU children have higher mortality than HIV-unexposed children [6, 8-11], predominantly driven by increased frequency and severity of common childhood infections, particularly respiratory disease $[6,8,9,12-15]$. Recent meta-analyses estimate twofold higher child mortality amongst HEU compared to HIV-unexposed children in the first 1-2 years after birth, with a similar risk persisting in children between 2 and 5 years of age $[10,11]$. Finally, a clear divide in the categorisation of studies comes from the use of ART. Studies from the pre-ART era have the benefit of exploring the effect of HIV exposure without the potential confounding effects of ART. However, they may be less relevant in the modern era where most HEU children are also ART-exposed. Although there are clear benefits from ART in reducing HIV transmission and improving maternal health, there is the potential for ART to have negative effects on the developing fetus, and separating the effects of HIV and ART exposure is challenging.

\section{Growth and Neurodevelopment of HEU Children}

An estimated 250 million (43\%) children under the age of 5 years fail to reach their developmental potential in lowand middle-income countries (LMIC), based on proxy measures of stunting and poverty [16*0]. Impaired growth and development have far-reaching consequences across the lifecourse, impacting academic outcomes, employment and longterm non-communicable disease risk, as well as intergenerational effects on health and human capital (Fig. 1). Emerging data indicate that this cycle may be critically influenced by HIV exposure.

\section{Growth Outcomes}

Linear growth is an important reflection of overall child wellbeing. In the largest cohort to date, Zimbabwean HEU children in the pre-ART era had $23 \%$ more stunting (lengthfor-age $Z$ score $<-2$ ) than HIV-unexposed children from the same communities by 12 months of age [17]. The effect of HIV exposure on growth in the ART era is less clear because there have been few studies to date. Reducing antenatal HIV exposure through ART control of maternal viraemia during pregnancy decreases the risk of transmission and may have additional benefits for HEU infants. However, intrauterine growth restriction and preterm birth have been associated with certain antiretroviral drugs in some studies [18•]. Findings from two large cohorts in the ART era have recently been reported in two different African settings. In Cape Town, where overall stunting prevalence was low, HEU children

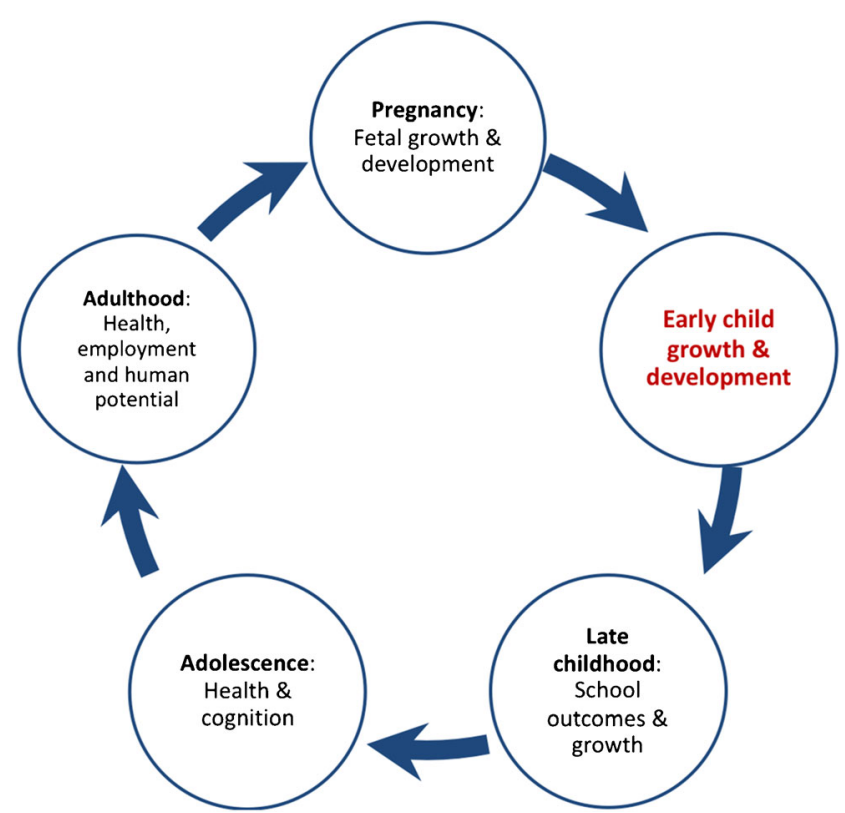

Fig. 1 The cycle of child growth and development 
had lower length-for-age $Z$ scores and almost threefold more stunting than HIV-unexposed children [19•]. In rural Zimbabwe, where overall stunting prevalence was high, HEU children also had lower length-for-age $Z$ scores and almost twice as much stunting [20]. Similar findings were seen for weight-for-age, underweight (weight-for-age $Z$ score $<-$ 2 ), head circumference and microcephaly (head circumference-for-age $Z$ - score $<-2$ ), although not weightfor-length or wasting (weight-for-length $Z$ score $<-2$ ) [20]. Collectively, these studies indicate that growth impairment continues to be a major problem amongst HEU children in the current PMTCT era.

\section{Neurodevelopmental Outcomes}

The negative impact of HIV infection on child brain development, both clinically and neuroradiologically, is wellestablished [21, 22]. There is increasing evidence that HIV exposure (without infection) may also be associated with neurodevelopmental impairment, although the manifestations are more subtle than for HIV-infected children [21, 23, 24••]. Studies from LMIC settings report an impact of HIV exposure on language [21-23, 24••, 25, 26], behaviour [21, 23], cognition $[24 \bullet \bullet, 26]$ and motor function [24••, 27], although there are limitations to these studies: most were from the pre-ART era, had small sample sizes and lacked adequate comparator groups. A large Zimbabwean study from the pre-ART era found that head circumference was consistently lower in HEU compared to HIV-unexposed infants throughout the first year after birth [28], but there were no neurodevelopmental evaluations in this cohort.

Recent studies in sub-Saharan Africa have generally supported findings from the pre-ART era. One study of South African HEU children aged 12 months found increased odds of cognitive (OR 2.28, 95\% CI 1.13, 4.60) and motor delay (OR 2.10, 95\% CI 1.03, 4.28) [29•], while another from Botswana showed increased expressive language delay (aOR $1.44,95 \%$ CI 1.01, 2.06) at 2 years [30]. HEU children aged 2 years in rural Zimbabwe had poorer motor and language development compared to their HIV-unexposed community counterparts [31] and the Drakenstein Child Health Study found receptive and expressive language delay in South African HEU children compared to HIV-unexposed children at 2 years of age [32•].

In contrast, a recent study from Uganda and Malawi did not find any neurodevelopmental differences in HEU children aged 1 to 5 years compared to an HIV-unexposed group [33•]. Similarly, evidence from HEU children in highincome settings has generally been reassuring [34, 35]. However, some language delay has been reported [36, 37] and there is a suggestion that cognition and behaviour may be affected at older ages [21, 23] [38]. A UK study found similar outcomes for HIV-infected adolescents and their uninfected siblings, and that both groups were impaired compared to normative data [39]. There are few studies of older HEU children in LMIC settings from the current ART era. One multisite study across five African countries did not find any cognitive differences compared to HIV-unexposed children [40], although language skills were not reported. Other studies have indicated potential ongoing delays, including poorer school mathematics performance in Zambia [41], and lower IQ, language and fine motor development in HEU children aged 2-12 years in Thailand and Cambodia [26].

Overall, although further research is needed, current evidence suggests HEU children may be at risk of delayed neurodevelopment in the early years of life, particularly in LMIC settings, and there are concerns regarding later school and behavioural outcomes.

\section{Pathogenesis-Universal Pathways Versus HIV-Specific Pathways?}

We hypothesise that there are two broad pathways through which HIV exposure without infection may impact child growth and development: (1) indirectly, by augmenting existing universal pathways that are known common risk factors for poor growth and development; and (2) directly, via HIV-specific mechanisms including exposure to HIV virions, immune activation and ART toxicity (Fig. 2).

\section{Augmentation of Universal Pathways}

Growth and development entail the interaction of genetically determined biological processes and environmental influences. The ecological model of development [42] describes the interacting nature of these internal and external factors over time. Both the cumulative burden and timing of these risks likely influence neurodevelopment [43]. Research suggests that HIV exposure may augment a range of universal risk factors, and below, we outline the available evidence.

\section{Intrauterine Infections}

Many in utero infections have consequences for the developing fetus. Cytomegalovirus (CMV), rubella, Zika virus, syphilis and toxoplasmosis have all been documented to impact child development [44]. HIV-infected mothers are at increased risk for some of these infections; several studies, although not all, have indicated that CMV in particular may be more prevalent in HIVaffected mothers and children [45, 46$]$ and may explain some of the adverse outcomes associated with HIV exposure [47]. 
Fig. 2 Conceptual framework of the hypothesised pathways through which HIV and ART exposure affect child growth and development. Red lines demarcate HIV-specific pathways; blue lines represent universal pathways. ART, antiretroviral therapy

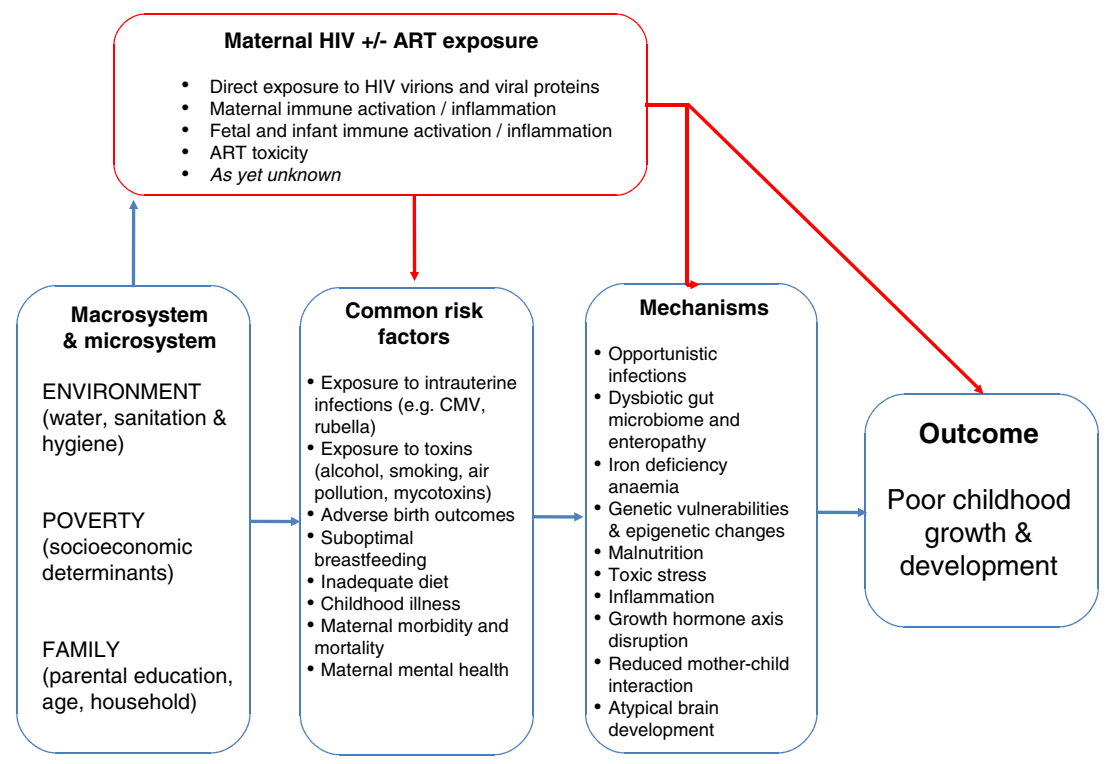

ART exposure has been associated with adverse birth outcomes. A recent meta-analysis found that HIV-positive women who conceived on ART had $41 \%$ greater risk of preterm delivery compared to HIV-positive women who started ART during pregnancy [18••]. A study from Botswana showed this risk is similar between efavirenz- and dolutegravir-containing regimens [62]; however, recent concerns have been raised around the safety of dolutegravir at the time of conception due to a potential increase in neural tube defects [63]. Further data on the impact of specific drugs and the relationship between poor birth outcomes and timing of ART initiation are urgently needed.

\section{Breastfeeding Practices}

Global recommendations are that breastfeeding should be early (initiated within $1 \mathrm{~h}$ of birth), exclusive (breastmilk and prescribed medications only for the first 6 months of life) and prolonged (through 2 years of age). Suboptimal breastfeeding increases morbidity and mortality, particularly in LMIC settings [64]. A review of 17 observational studies demonstrated that better cognitive outcomes were associated with optimal breastfeeding practices [65]. Findings from a 2015 analysis of the 1982 Pelotas birth cohort in Brazil also reported a dose-response association between breastfeeding duration and increased child cognitive performance, educational attainment and income at the age of 30 years [66]. Globally, guidance on infant feeding for HIV-positive mothers in LMIC settings has changed over time with the introduction of PMTCT and recognition of the benefits of breastfeeding, despite the risk of postnatal HIV transmission [67]. However, formula feeding to prevent postnatal HIV transmission through breastmilk means that HEU children continue to have lower rates of breastfeeding across the world, which may 
influence developmental outcomes. The impact of postnatal ART exposure through breastfeeding is still to be examined.

\section{Inadequate Diet}

Food insecurity in pregnancy is a risk factor for adverse birth outcomes and, during early childhood, has been associated with poor growth and neurodevelopment arising from complex mechanisms including nutritional insufficiencies and increased parental stress [68]. Children need sufficient nutrients for growth and immune development, and dietary diversity is necessary for optimal child outcomes. Food insecurity often coexists with HIV infection [69] and has been found to be associated with lower ART adherence, increased HIVassociated illness and decreased survival in HIV-infected individuals [70].

\section{Childhood IIIness}

Illnesses such as childhood pneumonia are associated with long-term physical sequelae [71]. If hospitalisation is needed, this may also have considerable impact on children and their families [72], causing separation from parents and reducing school attendance. Mounting evidence suggests HEU children have increased infectious morbidity $[6,15,73]$, and studies to date have found this is particularly due to viral and bacterial respiratory infections $[14,74,75]$ in early life. There is also evidence that HEU children are at risk for unusual infections [76], including Pneumocystis jirovecii [9, 77-82], CMV [79, $83,84]$ and haemorrhagic varicella $[12,77]$. Correspondingly, cohort studies from both LMIC and high-income settings suggest HEU children have a higher risk of hospitalisation during infancy [85-87] as well as elevated mortality [10]. In pre-ART era Zimbabwe, morbidity and mortality of HEU children were strongly associated with maternal HIV disease severity, and increased infectious morbidity amongst HEU children remained until maternal CD4 counts were $\geq 800$ cells $/ \mu \mathrm{L}$ [88]. In the ART era, a recent study from Belgium found that initiation of maternal ART prior to pregnancy (i.e. conception occurred on ART) appeared protective against infectious morbidity in HEU children; however, further work is needed to explore these findings in LMIC [86].

\section{Maternal IIIness and Death}

Maternal physical health before and after birth critically influences child growth and development. Mothers who are unwell may be less able to bond with and care for their children and maternal undernutrition is a risk factor for adverse birth outcomes [59, 89]. Furthermore, the loss of one or more parents, orphanhood and institutionalisation have severe repercussions [90]. There is extensive literature from the pre-ART era on the impact of parental death from HIV/AIDS, and it is estimated over 17 million children have lost one/both parents from the HIV/AIDS epidemic [90]. Parental death may affect children emotionally and impact subsequent relationships. Maternal death is itself related to outcomes of HEU infants [91], potentially for several reasons. First, an infant born to a mother with advanced disease may have greater immune abnormalities; second, mothers who are sick in the late stages of their illness may be unable to care for their children adequately, both physically and emotionally; and third, children who lose their mothers may be subject to extreme poverty and homelessness [92]. Even in the ART era, maternal HIV infection is associated with higher morbidity and mortality, and disease severity in HIV-infected mothers has been associated with infant health outcomes [93].

\section{Maternal Mental Health}

Maternal psychological illness is linked to adverse child health outcomes. Maternal depression is a risk factor for impaired child growth and development [94, 95]. Similarly, maternal stress has been found to have long-term repercussions on child psychological health [96]. In many communities, there is an association between maternal stress or depression and HIV [97], and the additional exposure to maternal mental health problems has been associated with risk of poor cognitive development in HEU children [98]. Maternal capabilities, which reflect the attributes required to care for a child, may be affected by HIV infection. HIV-infected parents who are unwell may be at risk of poverty because of an inability to work, which may affect availability of food and access to healthcare for the household. HEU children may be expected to take on caregiver roles for infected family members or may be neglected when other children in the family are HIV-infected [39]. Using models to approximate the effect of maternal HIV on young children in LMIC settings, it has been estimated that, in HIV-affected families, school completion falls from 61 to $57 \%$, and children have a $10 \%$ higher incidence of anxiety or depression than HIV-unexposed children [99-102].

\section{HIV-Specific Pathways}

Children born to HIV-infected mothers may be exposed to both HIV and ART antenatally, perinatally and/or postnatally. It is likely that in addition to the universal pathways discussed above, there are separate HIV-related mechanisms that impact on the child's growth and development including (i) directly through exposure to HIV virions, (ii) through effects of maternal immune activation/inflammation on the in utero environment, (iii) by promoting immune activation/inflammation in the fetus and/or child and (iv) via ART toxicity throughout the period of in utero development and breastfeeding. 


\section{Direct Exposure to HIV Virions and Viral Proteins}

HIV is a neurotropic virus, which can cause encephalopathy in HIV-infected infants, leading to microcephaly and neurodevelopmental impairment [21]. Neuropathology occurs directly, following exposure to HIV proteins that exhibit neurotoxicity, and indirectly via microglial activation and neuroinflammation. It is conceivable that antenatal exposure to HIV may affect brain development even without infection. Studies have detected HIV-specific immune responses in HEU children, suggesting that sufficient HIV antigen exposure occurs antenatally or perinatally to prime immune responses [103]. Direct exposure of the fetal brain to HIV virions and proteins may therefore be hypothesised to cause HIV-mediated neurotoxicity and impact brain growth and development. It is possible that in utero exposure to HIV virions may also modulate immune responses, resulting in adverse outcomes, similar to other chronic maternal infections including malaria, as discussed below [103].

\section{Maternal Immune Activation/Inflammation}

A healthy, regulated immune system is important for neurodevelopment [104]; therefore, HIV-related maternal immune activation and chronic systemic inflammation may impact fetal development. Advanced maternal HIV disease antenatally, which is driven by immune activation, has been consistently associated with HEU child morbidity [86]. Le Roux and colleagues recently found that the duration and severity of HIV viraemia in mothers during the antenatal period was closely related to developmental outcomes in their HEU infants, but immune activation was not assessed in this study [105]. Dysregulated immune mechanisms have been linked to various neurological disorders, and epidemiological associations exist between infections in pregnancy, maternal immune activation and schizophrenia, autism and epilepsy in offspring $[106,107]$, suggesting biological plausibility for this hypothesis in the setting of HIV. Further studies of HIV-positive mothers and HEU offspring are required in order to evaluate associations between inflammation in pregnancy and child development outcomes in these critical early years.

\section{Immune Activation/Inflammation in the HIV-Exposed Uninfected Child}

Immune activation and inflammation have been demonstrated in HIV-exposed fetuses and infants [108] which may trigger cytokine release, directly impacting cell migration and axonal growth and overall brain development [109-111, 112••]. Similarly, growth hormone axis disruption of Zimbabwean HEU children has been associated with systemic immune activation and the level of CMV replication [113]; inflammation in these infants was predominantly driven by higher HIV viral loads in mothers transmitting CMV [46]. Taken together, there appears to be a complex relationship between maternal HIV viraemia, early-life CMV acquisition, infant immune activation and the growth hormone axis, which may plausibly contribute to poor linear and brain growth in HEU children, and subsequent impaired neurodevelopment. Immune activation and inflammation may also drive neurodevelopmental impairment directly by impacting cell migration and axonal growth via proinflammatory cytokines $[112 \bullet \bullet]$.

\section{ART Toxicity}

Antiretrovirals cross the placental barrier with varying concentrations, and their potential effects on offspring growth and development continue to be investigated [114]. It is challenging to disentangle the effects of HIV and ART, particularly because treatment improves maternal health, which may offset any negative impact. Although ART is clearly essential both for maternal health and to reduce vertical transmission of HIV, exposure has been associated with adverse outcomes in some studies [25], including prematurity, poor growth, metabolic disturbance [115-117] and mitochondrial abnormalities [118-120]. Other studies have found no serious adverse effects [121, 122]. The Pediatric HIV/AIDS Cohort study (PHACS) has established the Surveillance Monitoring for ART Toxicities in HEU children (SMARTT) study to monitor for ART toxicities across a range of metabolic, growth, cardiac and neurological outcomes [123, 124]. Results indicate little adverse effect of maternal ART on child outcomes [35]; however, atazanavir has been found to potentially impact language acquisition [25, 35, 36, 125], and tenofovir has been associated with an adverse impact on bone mineral content [126]. Recently, concerns have been raised over neural tube defects following dolutegravir exposure at conception [127•]. Children may additionally be exposed to ART via breast milk or directly as prophylaxis. Transient haematological alterations, including anaemia, have been associated with zidovudine exposure [128]. Further pharmacovigilance is needed to document the long-term safety of individual antiretroviral drugs and treatment combinations [108].

\section{Mechanistic Pathways Mediating Impaired Growth and Development}

Universal and HIV-specific risk factors may drive poor growth and neurodevelopment through a common set of mechanistic pathways, as outlined in Fig. 2, including co-infections, inflammation, enteropathy, anaemia, nutrient deficiencies, epigenetic modifications and toxic stress, ultimately impacting brain development. However, we lack data on many of these pathogenic processes, meaning studies are needed to further our understanding of the pathways within this conceptual framework. Here, we provide some insights that support these 
mechanisms as potential mediators of the risk factors discussed above.

Direct exposure to opportunistic infections may cause neurotoxicity and impair growth. Congenital CMV infection in particular has been shown to have a profound impact on neurodevelopment, and the outcomes and mechanisms have been reviewed comprehensively elsewhere [129]. CMV acquisition in early life is very common in sub-Saharan Africa. The impact of CMV on growth and development may be even greater in HEU children and has recently been reviewed [45 •]. Garcia-Knight and colleagues found that CMV viral load in early infancy was negatively associated with weight-for-age and head circumference-for-age $Z$ scores in both HIV-exposed and HIV-unexposed children in rural Kenya [130], and Gompels and colleagues found that CMV was associated with growth and early child development in Zambia, particularly amongst those exposed to HIV [47].

Environmental enteric dysfunction (EED) is an almost ubiquitous subclinical disorder of the small intestine in LMIC. EED is characterised by villous atrophy, impaired gut barrier function, intestinal inflammation and microbial translocation, leading to systemic inflammation [131]. We have previously hypothesised that EED may be more severe amongst HEU compared to HIV-unexposed children [132], although a study of Zimbabwean infants at 6 weeks and 6 months of age showed similar levels of intestinal fatty acid binding protein (I-FABP), a marker of enterocyte damage, in HEU and HIV-unexposed infants. However, CRP was consistently higher in HEU compared to HIV-unexposed infants, highlighting that systemic inflammation is greater in the setting of HIV exposure, although the drivers of inflammation remain poorly defined [133]. Proinflammatory cytokines appear to be upregulated in HEU compared to HIV-unexposed children even at birth, and certain brain maturation processes such as cell migration and axonal growth may be particularly vulnerable to this inflammatory milieu [111].

A common co-morbidity with stunting is iron deficiency anaemia (IDA). IDA is a major cause of neurodevelopmental impairment [43] and has been identified as one of the leading causes of years lived with disability in children [134]. HIVexposed children have a higher frequency of anaemia than HIV-unexposed children $[135,136]$, plausibly driven by exposure to the virus itself and/or exposure to ART [137]. HIV infection is associated with other micronutrient deficiencies [52], and similar effects may be seen in HEU children, although data are currently lacking.

Early-life programming may be influenced by the in utero environment, causing DNA methylation and gene expression modifications [138]. These epigenetic modifications are now understood to have potential biological impact across the lifespan, leading to the theory of the developmental origins of health and disease and may have intergenerational effects [139]. HIV infection has been shown to lead to epigenome-wide differential DNA methylation in infected individuals [140]. Additionally, some studies have indicated that maternal HIV infection is associated with epigenetic modifications in neonates, and HIV and ART-exposed children have been found to have reduced DNA methylation in peripheral blood repetitive elements which may have long-term implications [141]. Further work is needed to understand this area; however, research into HIV-associated neurocognitive disorders (HAND) in adults indicates a role for genetic and epigenetic profiles in predicting vulnerability to the neurological effects of the virus and ART side effects [142].

Children living in adverse environments are at risk of chronic stress and persistent activation of their physiological stress response-a process known as toxic stress [143]. This process may act via the hypothalamic-pituitary-adrenal (HPA) axis and immune responses to disrupt healthy brain circuit development, particularly in the prefrontal cortex [144]. Through this impact on the neuroendocrine-immune (NEI) network, early experiences can fundamentally shape the developing brain architecture [143]. Early mutual interactions and experiences between children and key adults also shape the developing brain architecture and affect the NEI network [143]. Maternal physical and psychological illness coupled with a lack of social support may impact on a mother's ability to provide a safe and secure physical and emotional environment for her infant [145]. Similarly, growing up in an environment with inadequate stimulation or few early learning opportunities is associated with reduced cognitive development [146]. Children growing up in families affected by HIV may face multiple adversities that affect the parent-child relationship including parental illness and death, mental illness, and stress from emotional, financial and social pressures [147].

Ultimately, the risk factors and mechanisms identified here may modulate brain growth and network development. In addition, there may be other risk factors and mechanisms, including those as yet unknown, influencing these children. The in utero period and early postnatal life is a time of substantial brain growth, when extensive neural network development and maturation take place [7]. The developing brain during this time is particularly sensitive to environmental influences [148]. Animal models as well as human studies suggest that infection-induced maternal immune activation impacts developing neural circuits [106]. Studies have indicated that maternal immune activation and induction of proinflammatory cytokines affecting the microbiota-gut-brain axis or eliciting the stress response through the HPA axis result in atypical brain development of the fetus [107, 149, 150]. Neuroimaging study findings of HEU-associated white matter microstructural changes early in life $[110,151]$ 
suggest abnormal brain development as a potential mechanism for impaired child outcomes.

\section{Improving HEU Child Growth and Developmental Outcomes}

Healthy birth, growth and development form the foundations for later school performance, employment opportunities and long-term human capital and health. First and foremost, the continued global focus on reducing the burden of antenatal HIV infection is the key to eliminating HIV exposure in children. However, given the expanding population of HEU children, efforts that focus on prevention and intervention strategies to reduce the burden of poor HEU child outcomes are also needed [108].

\section{Prevention}

In order to develop successful prevention strategies, further research is needed to understand the effects of HIV exposure on child outcomes. Improved ART coverage in recent years means that family and home environments may be different to previous decades; infant feeding advice has shifted over time and the impact of breastfeeding patterns in this population is still being unravelled; children are now more commonly exposed to ART in utero and postnatally, and more women are conceiving on ART. Studies examining the relative contributions of HIVrelated pathways to growth and developmental impairment in the context of universal risk factors in the era of ART are needed to inform and focus these strategies [93]. In order to detect early adverse outcomes and intervene, pharmacovigilance systems are needed to assess effects of ART on the growing and developing child. This is particularly relevant with the introduction of new drugs and regimens, and new approaches to prevent HIV infection in pregnant and breastfeeding women using pre-exposure prophylaxis (PrEP). The concerns raised over dolutegravir safety at the time of conception provide lessons going forward [63]. Evaluating the relative safety of different ART regimens in pregnancy for HEU child growth, brain health and development is critical.

Some studies suggest there may be a high-risk subgroup within the HEU population vulnerable to adverse outcomes. Studies have found interactions between HIV exposure and preterm birth leading to poorer growth [19•] and worse cognitive and motor outcomes [29•], and also poorer outcomes in HEU children with CMV coinfection, compared to those without [47]. Further evidence is needed to define these high-risk subgroups, who may benefit from targeted prevention strategies, particularly where resources are limited. Initiating prevention before conception to optimise the health of mothers and their families will likely be most effective.

\section{Intervention}

Alongside the development of prevention policies, intervention strategies are needed to identify and support HEU children at risk of growth and developmental impairment to improve long-term outcomes. Evidence from institutionalised children suggests interventions need to be initiated early (before the age of 5 years) to reverse impairment during critical periods of growth and development; however, the optimal window of opportunity for HEU children remains unclear [43].

Targeting the universal risk factors that impact growth and development is a logical strategy, through improved breastfeeding, adequate nutrition, support for maternal physical and psychosocial health, reducing exposure to toxins, prevention and early treatment of childhood infections and reducing poverty. Integrating this with improved maternal ART adherence throughout the period of pregnancy and breastfeeding to ensure HIV viral suppression would also likely contribute to improved outcomes amongst HEU children. This may be delivered as integrated care through multisectoral platforms targeting health, nutrition and education, involving both the caregiver and the child to break the intergenerational cycle, using approaches such as the UNICEF Nurturing Care Framework.

Concurrently, research informing additional targeted interventions to address the HIV-related pathways by assessing scalable packages of care for early child growth and development are needed. Recently, the SHINE trial in rural Zimbabwe demonstrated that the combination of improved infant and young child feeding and improved water, sanitation and hygiene interventions resulted in better outcomes in both motor and language development amongst HEU children [152]. Further work is required to examine the most effective, scalable intervention strategies moving forward.

\section{Conclusions}

There are currently 14.8 million HEU children worldwide and this population continues to expand. Increasing evidence suggests these children, particularly in LMIC settings, have a disparity in growth and development compared to HIVunexposed children. Our conceptual framework highlights potential pathways linking HIV and/or ART exposure and adverse outcomes. We propose HEU children may be affected by accentuating existing universal risk factor pathways as well as through HIV-specific pathways, via final common pathogenic mechanisms. Overall, a multifactorial causal pathway is most likely to shape the growth and neurodevelopment of the 
HEU child. More research is critically needed in the era of universal ART, to understand these pathways further and inform prevention and intervention strategies.

\section{Compliance with Ethical Standards}

Conflict of Interest Catherine J. Wedderburn, Ceri Evans, Shunmay Yeung, Diana M. Gibb, Kirsten A. Donald and Andrew J. Prendergast declare no conflicts of interest. Catherine J. Wedderburn, Ceri Evans and Andrew J. Prendergast are supported by the Wellcome Trust (203525/Z/ 16/Z; 203905/Z/16/Z; 108065/Z/15/Z).

Human and Animal Rights and Informed Consent This review article contains studies with human subjects performed by the authors; all have complied with the applicable ethical standards. This article does not contain any studies with animal subjects performed by any of the authors.

Open Access This article is distributed under the terms of the Creative Commons Attribution 4.0 International License (http:// creativecommons.org/licenses/by/4.0/), which permits unrestricted use, distribution, and reproduction in any medium, provided you give appropriate credit to the original author(s) and the source, provide a link to the Creative Commons license, and indicate if changes were made.

\section{References}

Papers of particular interest, published recently, have been highlighted as:

- Of importance

•. Of major importance

1. UNICEF. Children and AIDS Seventh Stocktaking Report. 2016.

2. UNICEF. Statistical update 2015 [Available from: childrenandaids.org.

3. UNAIDS. AIDSinfo [Available from: http://aidsinfo.unaids.org.

4. UNAIDS. 2015 Progress report on the global plan: towards the elimination of new HIV infections among children by 2015 and keeping their mothers alive. UNAIDS Publications; 2015.

5. Slogrove AL, Becquet R, Chadwick EG, Cote HCF, Essajee S, Hazra R, et al. Surviving and thriving-shifting the public health response to HIV-exposed uninfected children: report of the 3rd HIV-Exposed Uninfected Child Workshop. Front Pediatr. 2018;6:157.

6. Evans C, Jones CE, Prendergast AJ. HIV-exposed, uninfected infants: new global challenges in the era of paediatric HIV elimination. Lancet Infect Dis. 2016;16(6):e92-e107.

7. Hermoye L, Saint-Martin C, Cosnard G, Lee SK, Kim J, Nassogne MC, et al. Pediatric diffusion tensor imaging: normal database and observation of the white matter maturation in early childhood. NeuroImage. 2006;29(2):493-504.

8. Newell ML, Coovadia H, Cortina-Borja M, Rollins N, Gaillard P, Dabis F, et al. Mortality of infected and uninfected infants born to HIV-infected mothers in Africa: a pooled analysis. Lancet. 2004;364(9441):1236-43.

9. Taron-Brocard C, Le Chenadec J, Faye A, Dollfus C, Goetghebuer $\mathrm{T}$, Gajdos V, et al. Increased risk of serious bacterial infections due to maternal immunosuppression in HIV-exposed uninfected infants in a European country. Clin Infect Dis. 2014;59(9):1332-45.
10. Arikawa S, Rollins N, Newell ML, Becquet R. Mortality risk and associated factors in HIV-exposed, uninfected children. Tropical Med Int Health. 2016;21(6):720-34.

11. Brennan AT, Bonawitz R, Gill CJ, Thea DM, Kleinman M, Useem $\mathrm{J}$, et al. A meta-analysis assessing all-cause mortality in HIVexposed uninfected compared with HIV-unexposed uninfected infants and children. Aids. 2016;30(15):2351-60.

12. Koyanagi A, Humphrey JH, Ntozini R, Nathoo K, Moulton LH, Iliff $\mathrm{P}$, et al. Morbidity among human immunodeficiency virusexposed but uninfected, human immunodeficiency virus-infected, and human immunodeficiency virus-unexposed infants in Zimbabwe before availability of highly active antiretroviral therapy. Pediatr Infect Dis J. 2011;30(1):45-51.

13. Marinda E, Humphrey JH, Iliff PJ, Mutasa K, Nathoo KJ, Piwoz EG, et al. Child mortality according to maternal and infant HIV status in Zimbabwe. Pediatr Infect Dis J. 2007;26(6):519-26.

14. le Roux DM, Nicol MP, Myer L, Vanker A, Stadler JAM, von Delft E, et al. Lower respiratory tract infections in children in a well-vaccinated South African birth cohort: spectrum of disease and risk factors. Clin Infect Dis. 2019.

15. Yeganeh N, Watts DH, Xu J, Kerin T, Joao EC, Pilotto JH, et al. Infectious morbidity, mortality and nutrition in HIV-exposed, uninfected, formula-fed infants: results from the HPTN 040/PACTG 1043 trial. Pediatr Infect Dis J. 2018;37(12):1271-8.

16.• Black MM, Walker SP, Fernald LCH, Andersen CT, DiGirolamo $\mathrm{AM}, \mathrm{Lu} \mathrm{C}$, et al. Early childhood development coming of age: science through the life course. Lancet. 2017;389(10064):77-90. A comprehensive exploration of the scientific understanding of early child development.

17. Omoni AO, Ntozini R, Evans C, Prendergast AJ, Moulton LH, Christian PS, et al. Child growth according to maternal and child HIV status in Zimbabwe. Pediatr Infect Dis J. 2017;36(9):869-76.

18. Uthman OA, Nachega JB, Anderson J, Kanters S, Mills EJ, Renaud F, et al. Timing of initiation of antiretroviral therapy and adverse pregnancy outcomes: a systematic review and meta-analysis. Lancet HIV. 2017;4(1):e21-30. Systematic review exploring the relationship between ART and pregnancy outcomes.

19. le Roux SM, Abrams EJ, Donald KA, Brittain K, Phillips TK, Nguyen KK, et al. Growth trajectories of breastfed HIV-exposed uninfected and HIV-unexposed children under conditions of universal maternal antiretroviral therapy: a prospective study. Lancet Child Adolesc Health. 2019;3(4):234-44. Recent study comparing growth outcomes in a large cohort of HEU and HIVunexposed children.

20. Evans C, Chasekwa B, Ntozini R, Majo FD, Mutasa K, Tavengwa $\mathrm{N}$, et al. Surviving and thriving? Outcomes of HIV-exposed children in rural Zimbabwe. Conference on Retroviruses and Opportunistic Infections (CROI); 4th-7th March; Seattle (WA) 2019

21. Le Doare K, Bland R, Newell ML. Neurodevelopment in children born to HIV-infected mothers by infection and treatment status. Pediatrics. 2012;130(5):e1326-44.

22. Hoare J, Ransford GL, Phillips N, Amos T, Donald K, Stein DJ. Systematic review of neuroimaging studies in vertically transmitted HIV positive children and adolescents. Metab Brain Dis. 2014;29(2):221-9.

23. Sherr L, Croome N, Parra Castaneda K, Bradshaw K. A systematic review of psychological functioning of children exposed to HIV: using evidence to plan for tomorrow's HIV needs. AIDS Behav. 2014;18(11):2059-74.

24.• McHenry MS, McAteer CI, Oyungu E, McDonald BC, Bosma CB, Mpofu PB, et al. Neurodevelopment in young children born to HIV-infected mothers: a meta-analysis. Pediatrics. 2018;141(2). Systematic review and meta-analysis comparing neurodevelopmental outcomes between HEU and HIVunexposed children. 
25. Desmonde S, Goetghebuer T, Thorne C, Leroy V. Health and survival of HIV perinatally exposed but uninfected children born to HIV-infected mothers. Curr Opin HIV AIDS. 2016;11(5):46576.

26. Kerr SJ, Puthanakit T, Vibol U, Aurpibul L, Vonthanak S, Kosalaraksa P, et al. Neurodevelopmental outcomes in HIVexposed-uninfected children versus those not exposed to HIV. AIDS Care. 2014;26(11):1327-35.

27. Van Rie A, Mupuala A, Dow A. Impact of the HIV/AIDS epidemic on the neurodevelopment of preschool-aged children in Kinshasa, Democratic Republic of the Congo. Pediatrics. 2008;122(1):e123-8.

28. Evans C, Chasekwa B, Ntozini R, Humphrey JH, Prendergast AJ. Head circumferences of children born to HIV-infected and HIVuninfected mothers in Zimbabwe during the preantiretroviral therapy era. Aids. 2016;30(15):2323-8.

29. le Roux SM, Donald KA, Brittain K, Phillips TK, Zerbe A, Nguyen KK, et al. Neurodevelopment of breastfed HIV-exposed uninfected and HIV-unexposed children in South Africa. Aids. 2018;32(13):1781-91. Recent study comparing neurodevelopmental outcomes in HEU and HIV-unexposed children.

30. Chaudhury S, Williams PL, Mayondi GK, Leidner J, Holding P, Tepper V, et al. Neurodevelopment of HIV-exposed and HIVunexposed uninfected children at 24 months. Pediatrics. 2017;140(4).

31. Chandna J, Evans C, Chasekwa B, Kandawasvika G, Tavengwa N, Mutasa B, et al. Early child development of HIV-exposed uninfected children in rural Zimbabwe. Conference on Retroviruses and Opportunistic Infections (CROI); 4th-7th March; Seattle (WA) 2019

32. Wedderburn CJ, Yeung S, Rehman AM, Stadler JAM, Nhapi RT, Barnett W, et al. Neurodevelopmental of HIV-exposed uninfected children in South Africa: Outcomes from an observational birth cohort study. Lancet Child Adolesc Heaelth. 2019. Recent study comparing neurodevelopmental outcomes in HEU and HIVunexposed children.

33. Boivin MJ, Maliwichi-Senganimalunje L, Ogwang LW, Kawalazira R, Sikorskii A, Familiar-Lopez I, et al. Neurodevelopmental effects of ante-partum and post-partum antiretroviral exposure in HIV-exposed and uninfected children versus HIV-unexposed and uninfected children in Uganda and Malawi: a prospective cohort study. Lancet HIV. 2019. Recent study comparing neurodevelopmental outcomes in HEU and HIV-unexposed children.

34. Alimenti A, Forbes JC, Oberlander TF, Money DM, Grunau RE, Papsdorf MP, et al. A prospective controlled study of neurodevelopment in HIV-uninfected children exposed to combination antiretroviral drugs in pregnancy. Pediatrics. 2006;118(4): e1139-45.

35. Sirois PA, Huo Y, Williams PL, Malee K, Garvie PA, Kammerer $\mathrm{B}$, et al. Safety of perinatal exposure to antiretroviral medications: developmental outcomes in infants. Pediatr Infect Dis J. 2013;32(6):648-55.

36. Rice ML, Zeldow B, Siberry GK, Purswani M, Malee K, Hoffman $\mathrm{HJ}$, et al. Evaluation of risk for late language emergence after in utero antiretroviral drug exposure in HIV-exposed uninfected infants. Pediatr Infect Dis J. 2013;32(10):e406-13.

37. Caniglia EC, Patel K, Huo Y, Williams PL, Kapetanovic S, Rich $\mathrm{KC}$, et al. Atazanavir exposure in utero and neurodevelopment in infants: a comparative safety study. Aids. 2016;30(8):1267-78.

38. Nozyce ML, Huo Y, Williams PL, Kapetanovic S, Hazra R, Nichols S, et al. Safety of in utero and neonatal antiretroviral exposure: cognitive and academic outcomes in HIV-exposed, uninfected children 5-13 years of age. Pediatr Infect Dis J. 2014;33(11):1128-33.
39. Judd A, Le Prevost M, Melvin D, Arenas-Pinto A, Parrott F, Winston A, et al. Cognitive function in young persons with and without perinatal HIV in the AALPHI cohort in England: role of non-HIV-related factors. Clin Infect Dis. 2016;63(10):1380-7.

40. Boivin MJ, Barlow-Mosha L, Chernoff MC, Laughton B, Zimmer $\mathrm{B}$, Joyce C, et al. Neuropsychological performance in African children with HIV enrolled in a multisite antiretroviral clinical trial. Aids. 2018;32(2):189-204.

41. Nicholson L, Chisenga M, Siame J, Kasonka L, Filteau S. Growth and health outcomes at school age in HIV-exposed, uninfected Zambian children: follow-up of two cohorts studied in infancy. BMC Pediatr. 2015;15:66.

42. Bronfenbrenner U. The ecology of human development: experiments by nature and design. Cambridge, MA: Harvard University Press; 1979.

43. Walker SP, Wachs TD, Grantham-McGregor S, Black MM, Nelson CA, Huffman SL, et al. Inequality in early childhood: risk and protective factors for early child development. Lancet. 2011;378(9799):1325-38.

44. Panchaud A, Stojanov M, Ammerdorffer A, Vouga M, Baud D. Emerging role of Zika virus in adverse fetal and neonatal outcomes. Clin Microbiol Rev. 2016;29(3):659-94.

45. Filteau S, Rowland-Jones S. Cytomegalovirus infection may contribute to the reduced immune function, growth, development, and health of HIV-exposed, uninfected African children. Front Immunol. 2016;7:257. A comprehensive review evaluating the role of CMV in driving adverse health outcomes of HEU children.

46. Evans C, Chasekwa B, Rukobo S, Govha M, Mutasa K, Ntozini $\mathrm{R}$, et al. CMV acquisition and inflammation in HIV-exposed uninfected Zimbabwean infants. J Infect Dis. 2016:jiw630.

47. Gompels UA, Larke N, Sanz-Ramos M, Bates M, Musonda K, Manno D, et al. Human cytomegalovirus infant infection adversely affects growth and development in maternally HIV-exposed and unexposed infants in Zambia. Clin Infect Dis. 2012;54(3):434-42.

48. Donald KAM, Fernandez A, Claborn K, Kuo C, Koen N, Zar H, et al. The developmental effects of HIV and alcohol: a comparison of gestational outcomes among babies from South African communities with high prevalence of HIV and alcohol use. AIDS Res Ther. 2017;14(1):28.

49. Guille C, Aujla R. Developmental consequences of prenatal substance use in children and adolescents. J Child Adolesc Psychopharmacol. 2019.

50. Lombard MJ. Mycotoxin exposure and infant and young child growth in Africa: what do we know? Ann Nutr Metab. 2014;64(Suppl 2):42-52.

51. Anderson SM, Naidoo RN, Pillay Y, Tiloke C, Muttoo S, Asharam $\mathrm{K}$, et al. HIV induced nitric oxide and lipid peroxidation, influences neonatal birthweight in a South African population. Environ Int. 2018;121(Pt 1):1-12.

52. Obuseh FA, Jolly PE, Kulczycki A, Ehiri J, Waterbor J, Desmond RA, et al. Aflatoxin levels, plasma vitamins A and E concentrations, and their association with HIV and hepatitis B virus infections in Ghanaians: a cross-sectional study. J Int AIDS Soc. 2011;14:53.

53. Asiki G, Seeley J, Srey C, Baisley K, Lightfoot T, Archileo K, et al. A pilot study to evaluate aflatoxin exposure in a rural Ugandan population. Trop Med Int Health. 2014;19(5):592-9.

54. Smith LE, Stoltzfus RJ, Prendergast A. Food chain mycotoxin exposure, gut health, and impaired growth: a conceptual framework. Adv Nutr. 2012;3(4):526-31.

55. Mwaniki MK, Atieno M, Lawn JE, Newton CR. Long-term neurodevelopmental outcomes after intrauterine and neonatal insults: a systematic review. Lancet. 2012;379(9814):445-52. 
56. Vollmer B, Edmonds CJ. School age neurological and cognitive outcomes of fetal growth retardation or small for gestational age birth weight. Front Endocrinol (Lausanne). 2019;10:186.

57. Collins A, Weitkamp JH, Wynn JL. Why are preterm newborns at increased risk of infection? Arch Dis Child Fetal Neonatal Ed. 2018;103(4):F391-F4.

58. Wedi COO, Kirtley S, Hopewell S, Corrigan R, Kennedy SH, Hemelaar J. Perinatal outcomes associated with maternal HIV infection: a systematic review and meta-analysis. The Lancet HIV. 2016;3(1):e33-48.

59. Black RE, Victora CG, Walker SP, Bhutta ZA, Christian P, de Onis $\mathrm{M}$, et al. Maternal and child undernutrition and overweight in lowincome and middle-income countries. Lancet. 2013;382(9890): 427-51.

60. Malaba TR, Phillips T, Le Roux S, Brittain K, Zerbe A, Petro G, et al. Antiretroviral therapy use during pregnancy and adverse birth outcomes in South African women. Int J Epidemiol. 2017:46(5):1678-89.

61. Santosa WB, Staines-Urias E, Tshivuila-Matala COO, Norris SA, Hemelaar J. Perinatal outcomes associated with maternal HIV and antiretroviral therapy in pregnancies with accurate gestational age in South Africa. Aids. 2019.

62. Zash R, Jacobson DL, Diseko M, Mayondi G, Mmalane M, Essex $\mathrm{M}$, et al. Comparative safety of dolutegravir-based or efavirenzbased antiretroviral treatment started during pregnancy in Botswana: an observational study. Lancet Glob Health. 2018;6(7):e804-e10.

63. The L. Dolutegravir for HIV: a lesson in pregnancy safety research. The Lancet. 2018;391(10137).

64. Victora CG, Bahl R, Barros AJ, Franca GV, Horton S, Krasevec J, et al. Breastfeeding in the 21st century: epidemiology, mechanisms, and lifelong effect. Lancet. 2016;387(10017):475-90.

65. Horta BL, Loret de Mola C, Victora CG. Breastfeeding and intelligence: a systematic review and meta-analysis. Acta Paediatr. 2015;104(467):14-9.

66. Victora CG, Horta BL, Loret de Mola C, Quevedo L, Pinheiro RT, Gigante DP, et al. Association between breastfeeding and intelligence, educational attainment, and income at 30 years of age: a prospective birth cohort study from Brazil. Lancet Glob Health. 2015;3(4):e199-205.

67. Prendergast AJ, Goga AE, Waitt C, Gessain A, Taylor GP, Rollins $\mathrm{N}$, et al. Transmission of CMV, HTLV-1, and HIV through breastmilk. Lancet Child Adolesc Health. 2019;3(4):264-73.

68. Johnson AD, Markowitz AJ. Associations between household food insecurity in early childhood and children's kindergarten skills. Child Dev. 2018;89(2):e1-e17.

69. Garcia J, Hromi-Fiedler A, Mazur RE, Marquis G, Sellen D, Lartey A, et al. Persistent household food insecurity, HIV, and maternal stress in peri-urban Ghana. BMC Public Health. 2013;13:215

70. Anema A, Vogenthaler N, Frongillo EA, Kadiyala S, Weiser SD. Food insecurity and HIV/AIDS: current knowledge, gaps, and research priorities. Curr HIV/AIDS Rep. 2009;6(4):224-31.

71. Edmond K, Scott S, Korczak V, Ward C, Sanderson C, Theodoratou E, et al. Long term sequelae from childhood pneumonia; systematic review and meta-analysis. PLoS One. 2012;7(2):e31239.

72. Prugh DG, Staub EM, Sands HH, Kirschbaum RM, Lenihan EA. A study of the emotional reactions of children and families to hospitalization and illness. Am J Orthop. 1953;23(1):70-106.

73. Slogrove AL, Goetghebuer T, Cotton MF, Singer J, Bettinger JA. Pattern of infectious morbidity in HIV-exposed uninfected infants and children. Front Immunol. 2016;7:164.

74. Cohen C, Moyes J, Tempia S, Groome M, Walaza S, Pretorius M, et al. Epidemiology of acute lower respiratory tract infection in HIV-exposed uninfected infants. Pediatrics. 2016;137(4).
75. le Roux DM, Myer L, Nicol MP, Zar HJ. Incidence and severity of childhood pneumonia in the first year of life in a South African birth cohort: the Drakenstein Child Health Study. Lancet Glob Health. 2015;3(2):e95-e103.

76. von Mollendorf C, von Gottberg A, Tempia S, Meiring S, de Gouveia L, Quan V, et al. Increased risk for and mortality from invasive pneumococcal disease in HIV-exposed but uninfected infants aged $<1$ year in South Africa, 2009-2013. Clin Infect Dis. 2015;60(9):1346-56.

77. Slogrove AL, Cotton MF, Esser MM. Severe infections in HIVexposed uninfected infants: clinical evidence of immunodeficiency. J Trop Pediatr. 2010;56(2):75-81.

78. Morrow BM, Samuel CM, Zampoli M, Whitelaw A, Zar HJ. Pneumocystis pneumonia in South African children diagnosed by molecular methods. BMC Res Notes. 2014;7:26.

79. McNally LM, Jeena PM, Gajee K, Thula SA, Sturm AW, Cassol $\mathrm{S}$, et al. Effect of age, polymicrobial disease, and maternal HIV status on treatment response and cause of severe pneumonia in South African children: a prospective descriptive study. Lancet. 2007;369(9571):1440-51.

80. Heresi GP, Caceres E, Atkins JT, Reuben J, Doyle M. Pneumocystis carinii pneumonia in infants who were exposed to human immunodeficiency virus but were not infected: an exception to the AIDS surveillance case definition. Clin Infect Dis. 1997;25(3):739-40.

81. Jeena PM, Bobat B, Thula SA, Adhikari M. Children with Pneumocystis jiroveci pneumonia and acute hypoxaemic respiratory failure admitted to a PICU, Durban, South Africa. Arch Dis Child. 2008;93(6):545.

82. Morrow BM, Hsaio NY, Zampoli M, Whitelaw A, Zar HJ. Pneumocystis pneumonia in South African children with and without human immunodeficiency virus infection in the era of highly active antiretroviral therapy. Pediatr Infect Dis J. 2010;29(6):535-9.

83. Zash RM, Shapiro RL, Leidner J, Wester C, McAdam AJ, Hodinka RL, et al. The aetiology of diarrhoea, pneumonia and respiratory colonization of HIV-exposed infants randomized to breast- or formula-feeding. Paediatr Int Child Health. 2016;36(3):189-97.

84. Hsiao NY, Zampoli M, Morrow B, Zar HJ, Hardie D. Cytomegalovirus viraemia in HIV exposed and infected infants: prevalence and clinical utility for diagnosing CMV pneumonia. J Clin Virol. 2013;58(1):74-8.

85. Slogrove A, Reikie B, Naidoo S, De Beer C, Ho K, Cotton M, et al. HIV-exposed uninfected infants are at increased risk for severe infections in the first year of life. J Trop Pediatr. 2012;58(6):505-8.

86. Goetghebuer T, Smolen KK, Adler C, Das J, McBride T, Smits G, et al. Initiation of anti-retroviral therapy before pregnancy reduces the risk of infection-related hospitalization in HIV-exposed uninfected infants born in a high-income country. Clin Infect Dis. 2018.

87. Ruperez M, Gonzalez R, Maculuve S, Quinto L, Lopez-Varela E, Augusto O, et al. Maternal HIV infection is an important health determinant in non-HIV-infected infants. Aids. 2017;31(11): 1545-53.

88. Evans C, Humphrey JH, Ntozini R, Prendergast AJ. HIV-exposed uninfected infants in Zimbabwe: insights into health outcomes in the pre-antiretroviral therapy era. Front Immunol. 2016;7:190.

89. Khan MN, Rahman MM, Shariff AA, Rahman MM, Rahman MS, Rahman MA. Maternal undernutrition and excessive body weight and risk of birth and health outcomes. Arch Public Health. 2017;75:12.

90. Leyenaar JK. HIV/AIDS and Africa's orphan crisis. Paediatr Child Health. 2005;10(5):259-60. 
91. Newell M, Coovadia, H, Cortina-Borja, M, et al. Mortality of infected and uninfected infants born to HIV infected mothers in Africa: a pooled analysis. Lancet. 2004;364(1236-43).

92. UNAIDS/UNICEF/USAID. Children on the Brink 2004: A joint report of new orphan estimates and a framework for action. In: UNAIDS/UNICEF/USAID, editor. http://www.uniceforg/ publications/cob_layout6-013pdf2004.

93. le Roux SM, Abrams EJ, Nguyen K, Myer L. Clinical outcomes of HIV-exposed, HIV-uninfected children in sub-Saharan Africa. Trop Med Int Health. 2016;21(7):829-45.

94. Surkan PJ, Kennedy CE, Hurley KM, Black MM. Maternal depression and early childhood growth in developing countries: systematic review and meta-analysis. Bull World Health Organ. 2011;89(8):608-15.

95. Rahman A, Patel V, Maselko J, Kirkwood B. The neglected ' $m$ ' in $\mathrm{MCH}$ programmes - why mental health of mothers is important for child nutrition. Trop Med Int Health. 2008;13(4):579-83.

96. Essex MJ, Klein MH, Cho E, Kalin NH. Maternal stress beginning in infancy may sensitize children to later stress exposure: effects on cortisol and behavior. Biol Psychiatry. 2002;52(8):776-84.

97. Rubin LH, Maki PM. HIV, depression, and cognitive impairment in the era of effective antiretroviral therapy. Curr HIV/AIDS Rep. 2019;16(1):82-95.

98. Mebrahtu H, Simms V, Chingono R, Mupambireyi Z, Weiss HA, Ndlovu P, et al. Postpartum maternal mental health is associated with cognitive development of HIV-exposed infants in Zimbabwe: a cross-sectional study. AIDS care. 2018;30(sup2):74-82.

99. Desmond C, Bruce F, Tomlinson M, Marlow MB, Aber JL, Ouifki $\mathrm{R}$, et al. Modelling the long-term impacts on affected children of adult HIV: benefits, challenges and a possible approach. AIDS. 2014;28(Suppl 3):S269-75.

100. Sherr L, Cluver LD, Betancourt TS, Kellerman SE, Richter LM, Desmond C. Evidence of impact: health, psychological and social effects of adult HIV on children. AIDS. 2014;28(Suppl 3):S251S9.

101. Stein A, Desmond C, Garbarino J, Van Ijzendoorn MH, Barbarin $\mathrm{O}$, Black MM, et al. Predicting long-term outcomes for children affected by HIV and AIDS: perspectives from the scientific study of children's development. AIDS. 2014;28(Suppl 3):S261-S8.

102. The United States President's Emergency Plan for AIDS Relief. Consequences of adult HIV for affected children: modelling the impact 2014 [Available from: http://www.pepfar.gov/ awarenessdays/reports/232486.htm.

103. Afran L, Garcia Knight M, Nduati E, Urban BC, Heyderman RS, Rowland-Jones SL. HIV-exposed uninfected children: a growing population with a vulnerable immune system? Clin Exp Immunol. 2014;176(1):11-22.

104. Tanabe S, Yamashita T. The role of immune cells in brain development and neurodevelopmental diseases. Int Immunol. 2018;30(10):437-44.

105. le Roux SM, Donald KA, Kroon M, Phillips TK, Lesosky M, Esterhuyse L, et al. HIV viremia during pregnancy and neurodevelopment of HIV-exposed uninfected children in the context of universal antiretroviral therapy and breastfeeding: a prospective study. Pediatr Infect Dis J. 2018.

106. Knuesel I, Chicha L, Britschgi M, Schobel SA, Bodmer M, Hellings JA, et al. Maternal immune activation and abnormal brain development across CNS disorders. Nat Rev Neurol. 2014;10(11):643-60.

107. Estes ML, McAllister AK. Maternal immune activation: implications for neuropsychiatric disorders. Science. 2016;353(6301): $772-7$.

108. Mofenson LM. Editorial commentary: New challenges in the elimination of pediatric HIV infection: the expanding population of HIV-exposed but uninfected children. Clin Infect Dis. 2015;60(9):1357-60.
109. Krogh KA, Green MV, Thayer S. HIV-1 Tat-induced changes in synaptically-driven network activity adapt during prolonged exposure. Current HIV Research. 2015;12(6):406.

110. Tran LT, Roos A, Fouche JP, Koen N, Woods RP, Zar HJ, et al. White matter microstructural integrity and neurobehavioral outcome of HIV-exposed uninfected neonates. Medicine. 2016;95(4):e2577.

111. Bilbo SD, Schwarz JM. The immune system and developmental programming of brain and behavior. Front Neuroendocrinol. 2012;33(3):267-86.

112.• Abu-Raya B, Kollmann TR, Marchant A, MacGillivray DM. The immune system of HIV-exposed uninfected infants. Front Immunol. 2016;7:383. A comprehensive review focussed on immunology of HEU children.

113. Evans C, Chasekwa B, Rukobo S, Govha M, Mutasa K, Ntozini R, et al. Inflammation, CMV and the growth hormone axis in HVexposed uninfected infants. Conference on Retroviruses and Opportunistic Infections (CROI); 4th-7th March; Boston (MA)2018.

114. McCormack SA, Best BM. Protecting the fetus against HIV infection: a systematic review of placental transfer of antiretrovirals. Clin Pharmacokinet. 2014;53(11):989-1004.

115. Jao J, Abrams EJ. Metabolic complications of in utero maternal HIV and antiretroviral exposure in HIV-exposed infants. Pediatr Infect Dis J. 2014;33(7):734-40.

116. Powis KM, Smeaton L, Ogwu A, Lockman S, Dryden-Peterson S, van Widenfelt E, et al. Effects of in utero antiretroviral exposure on longitudinal growth of HIV-exposed uninfected infants in Botswana. J Acquir Immune Defic Syndr. 2011;56(2):131-8.

117. Hofer CB, Keiser O, Zwahlen M, Lustosa CS, Frota AC, de Oliveira RH, et al. In utero exposure to antiretroviral drugs: effect on birth weight and growth among HIV-exposed uninfected children in Brazil. Pediatr Infect Dis J. 2016;35(1):71-7.

118. Blanche S, Tardieu M, Rustin P, Slama A, Barret B, Firtion G, et al. Persistent mitochondrial dysfunction and perinatal exposure to antiretroviral nucleoside analogues. Lancet. 1999;354(9184): 1084-9.

119. Barret B, Tardieu M, Rustin P, Lacroix C, Chabrol B, Desguerre I, et al. Persistent mitochondrial dysfunction in HIV-1-exposed but uninfected infants: clinical screening in a large prospective cohort. Aids. 2003;17(12):1769-85.

120. Brogly SB, Ylitalo N, Mofenson LM, Oleske J, Van Dyke R, Crain MJ, et al. In utero nucleoside reverse transcriptase inhibitor exposure and signs of possible mitochondrial dysfunction in HIVuninfected children. Aids. 2007;21(8):929-38.

121. Connor EM, Sperling RS, Gelber R, Kiselev P, Scott G, O'Sullivan MJ, et al. Reduction of maternal-infant transmission of human immunodeficiency virus type 1 with zidovudine treatment. Pediatric AIDS Clinical Trials Group Protocol 076 Study Group. N Engl J Med. 1994;331(18):1173-80.

122. Petra Study T. Efficacy of three short-course regimens of zidovudine and lamivudine in preventing early and late transmission of HIV-1 from mother to child in Tanzania, South Africa, and Uganda (Petra study): a randomised, double-blind, placebocontrolled trial. Lancet. 2002;359(9313):1178-86.

123. Sirois PA, Chernoff MC, Malee KM, Garvie PA, Harris LL, Williams PL, et al. Associations of memory and executive functioning with academic and adaptive functioning among youth with perinatal HIV exposure and/or infection. J Pediatric Infect Dis Soc. 2016;5(suppl 1):S24-32.

124. Williams PL, Hazra R, Van Dyke RB, Yildirim C, Crain MJ, Seage GR 3rd, et al. Antiretroviral exposure during pregnancy and adverse outcomes in HIV-exposed uninfected infants and children using a trigger-based design. Aids. 2016;30(1):133-44.

125. Himes SK, Huo Y, Siberry GK, Williams PL, Rice ML, Sirois PA, et al. Meconium atazanavir concentrations and early language 
outcomes in HIV-exposed uninfected infants with prenatal atazanavir exposure. J Acquir Immune Defic Syndr. 2015;69(2): $178-86$.

126. Siberry GK, Jacobson DL, Kalkwarf HJ, Wu JW, DiMeglio LA, Yogev R, et al. Lower newborn bone mineral content associated with maternal use of tenofovir disoproxil fumarate during pregnancy. Clin Infect Dis. 2015;61(6):996-1003.

127. Zash R, Makhema J, Shapiro RL. Neural-tube defects with dolutegravir treatment from the time of conception. The New England Journal of Medicine. 2018;379(10):979-81. Report of signal of increased prevalence of neural tube defects in children born to mothers taking dolutegravir-based ART regimens.

128. Dryden-Peterson S, Shapiro RL, Hughes MD, Powis K, Ogwu A, Moffat $\mathrm{C}$, et al. Increased risk of severe infant anemia after exposure to maternal HAART, Botswana. J Acquir Immune Defic Syndr. 2011;56(5):428-36.

129. Cheeran MC, Lokensgard JR, Schleiss MR. Neuropathogenesis of congenital cytomegalovirus infection: disease mechanisms and prospects for intervention. Clin Microbiol Rev. 2009;22(1):99 126 Table of contents.

130. Garcia-Knight MA, Nduati E, Hassan AS, Nkumama I, Etyang TJ, Hajj NJ, et al. Cytomegalovirus viraemia is associated with poor growth and T-cell activation with an increased burden in HIV-exposed uninfected infants. Aids. 2017;31(13):1809-18.

131. Prendergast A, Kelly P. Enteropathies in the developing world: neglected effects on global health. Am J Trop Med Hyg. 2012;86(5):756-63.

132. Humphrey JH, Jones AD, Manges A, Mangwadu G, Maluccio JA, Mbuya MN, et al. The sanitation hygiene infant nutrition efficacy (SHINE) trial: rationale, design, and methods. Clin Infect Dis. 2015;61(Suppl 7):S685-702.

133. Prendergast AJ, Chasekwa B, Rukobo S, Govha M, Mutasa K, Ntozini R, et al. Intestinal damage and inflammatory biomarkers in human immunodeficiency virus (HIV)-exposed and HIVinfected Zimbabwean infants. J Infect Dis. 2017;216(6):651-61.

134. Global Burden of Disease Pediatrics C, Kyu HH, Pinho C, Wagner JA, Brown JC, Bertozzi-Villa A, et al. Global and national burden of diseases and injuries among children and adolescents between 1990 and 2013: findings from the Global Burden of Disease 2013 Study. JAMA Pediatr. 2016;170(3):267-87.

135. Moraleda C, de Deus N, Serna-Bolea C, Renom M, Quintó L, Macete E, et al. Impact of HIV exposure on health outcomes in HIV-negative infants born to HIV-positive mothers in SubSaharan Africa. J Acquir Immune Defic Syndr. 2014;65(2):182-9.

136. Mwinga K, Vermund SH, Chen YQ, Mwatha A, Read JS, Urassa $\mathrm{W}$, et al. Selected hematologic and biochemical measurements in African HIV-infected and uninfected pregnant women and their infants: the HIV Prevention Trials Network 024 protocol. BMC Pediatr. 2009;9:49.

137. Rovira N, Noguera-Julian A, Rives S, Berrueco R, Lahoz R, Fortuny $\mathrm{C}$. Influence of new antiretrovirals on hematological toxicity in HIV-exposed uninfected infants. Eur J Pediatr. 2016;175(7):1013-7.

138. Williams TC, Drake AJ. What a general paediatrician needs to know about early life programming. Arch Dis Child. 2015;100(11):1058-63.
139. Wadhwa PD, Buss C, Entringer S, Swanson JM. Developmental origins of health and disease: brief history of the approach and current focus on epigenetic mechanisms. Semin Reprod Med. 2009;27(5):358-68.

140. Zhang X, Justice AC, Hu Y, Wang Z, Zhao H, Wang G, et al. Epigenome-wide differential DNA methylation between HIVinfected and uninfected individuals. Epigenetics. 2016;11(10): 750-60.

141. Marsit CJ, Brummel SS, Kacanek D, Seage GR 3rd, Spector SA, Armstrong DA, et al. Infant peripheral blood repetitive element hypomethylation associated with antiretroviral therapy in utero. Epigenetics. 2015;10(8):708-16.

142. Gomez D, Power C, Fujiwara E. Neurocognitive impairment and associated genetic aspects in HIV infection. Curr Top Behav Neurosci. 2018

143. Johnson SB, Riley AW, Granger DA, Riis J. The science of early life toxic stress for pediatric practice and advocacy. Pediatrics. 2013;131(2):319-27.

144. Shonkoff JP, Garner AS, Committee on Psychosocial Aspects of C, Family H, Committee on Early Childhood A, Dependent C, et al. The lifelong effects of early childhood adversity and toxic stress. Pediatrics. 2012;129(1):e232-46.

145. Ford ND, Stein AD. Risk factors affecting child cognitive development: a summary of nutrition, environment, and maternal-child interaction indicators for sub-Saharan Africa. J Dev Orig Health Dis. 2016;7(2):197-217.

146. Walker SP, Chang SM, Powell CA, Grantham-McGregor SM. Effects of early childhood psychosocial stimulation and nutritional supplementation on cognition and education in growth-stunted Jamaican children: prospective cohort study. Lancet. 2005;366(9499):1804-7.

147. Stein A, Desmond C, Garbarino J, Van IMH, Barbarin O, Black MM, et al. Predicting long-term outcomes for children affected by HIV and AIDS: perspectives from the scientific study of children's development. Aids. 2014;28(Suppl 3):S261-8.

148. Cheong JL, Hunt RW, Anderson PJ, Howard K, Thompson DK, Wang HX, et al. Head growth in preterm infants: correlation with magnetic resonance imaging and neurodevelopmental outcome. Pediatrics. 2008;121(6):e1534-40.

149. Ratnayake U, Quinn T, Walker DW, Dickinson H. Cytokines and the neurodevelopmental basis of mental illness. Front Neurosci. 2013;7:180.

150. Scola G, Duong A. Prenatal maternal immune activation and brain development with relevance to psychiatric disorders. Neuroscience. 2017;346:403-8.

151. Jankiewicz M, Holmes MJ, Taylor PA, Cotton MF, Laughton B, van der Kouwe AJW, et al. White matter abnormalities in children with HIV infection and exposure. Front Neuroanat. 2017;11:88.

152. Ntozini R, Chandna J, Evans C, Kandawasvika G, Chasekwa B, Majo $\mathrm{F}$, et al. Impact of improved nutrition/sanitation on neurodevelopment of HIV-exposed children. Conference on Retroviruses and Opportunistic Infections (CROI); 4th-7th March; Seattle (WA)2019.

Publisher's Note Springer Nature remains neutral with regard to jurisdictional claims in published maps and institutional affiliations. 